\title{
Erratum to: Routine Invasive Versus Conservative Management Strategies in Acute Coronary Syndrome: Time for a "Hybrid" Approach
}

Pravin Pratap $\cdot$ Sameer Gupta $\cdot$ Michael Berlowitz

Published online: 20 January 2012

(C) Springer Science+Business Media, LLC 2012

Erratum to: J. of Cardiovasc. Trans. Res.

DOI 10.1007/s12265-011-9333-8

Please note that the third coauthor's last name was misspelled in the article as published.

The correct spelling of the name is: Berlowitz (not Berlowtiz)

The online version of the original article can be found at http://dx.doi. org/10.1007/s12265-011-9333-8.

P. Pratap $\cdot$ S. Gupta $\cdot$ M. Berlowitz $(\bowtie)$

Department of Cardiovascular Sciences,

University of South Florida,

STC Building, 5th Floor 2 Tampa General Circle,

Tampa, FL 33606, USA

e-mail: mberlowi@health.usf.edu 